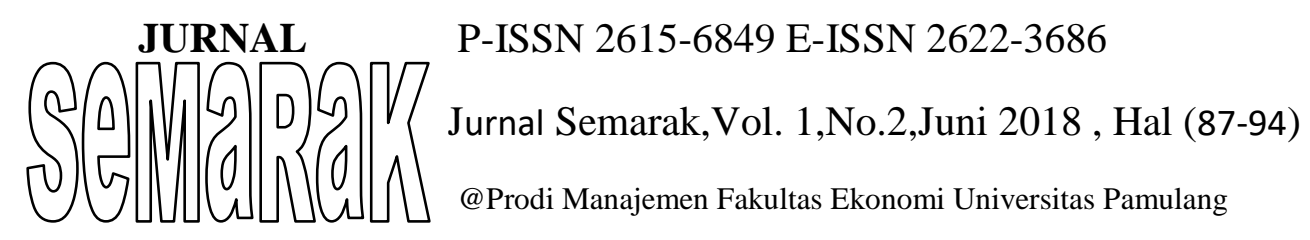

\title{
PENGARUH CURRENT RATIO DAN DEBT TO EQUITY RATIO TERHADAP RETURN ON INVESTMENT PADA PT. BHUWANATALA INDAH PERMAI, TBK PERIODE 2007-2015
}

\author{
Nani Rusnaeni \\ Dosen Fakultas Ekonomi Universitas Pamulang \\ Email :
}

\begin{abstract}
ABSTRAK
Tujuan dari penelitian adalah : Mengetahui tingkat Current Ratio (CR), Debt to Equity Ratio (DER) dan Return On Investment (ROI) pada PT. Bhuwanatala Indah Permai Tbk, serta guna mengetahui pengaruh Current Ratio (CR) dan Debt to Equity Ratio (DER) baik secara parsial maupun simultan terhadap Return On Investment (ROI) PT. Bhuwanatala Indah Permai periode 2007-2015.

Metode penelitian menggunakan pendekatan deskriptif asosiatif dengan pendekatan hipotesis. Populasi penelitian ini adalah laporan keuangan PT Bhuwanatala Indah Permai dengan sampel yang terdiri dari laporan neraca dan laba rugi perusahaan tahun 2007-2015.

Analisis data yang digunakan dalam penelitian ini adalah analisis regresi linear sederhana, analisis regresi linear berganda, uji asumsi klasik yang meliputi uji normalitas, uji multikolinearitas, uji autokorelasi, dan uji heteroskedastisitas. Uji signifikansi parsial (uji t) DER diperoleh t hitung ($2,580)<(2,447)$ serta signfikansi $0,036<0,05$ artinya DER berpengaruh signifikan terhadap ROI. Kemudian analisis regresi linear berganda diperoleh persamaan regresi $\mathrm{Y}=10,393+0,015 \mathrm{X}_{1}+(-$ $0,174) \mathrm{X}_{2}$. Uji simultan (uji F) diperoleh $\mathrm{f}$ hitung $(2,893)<\mathrm{f}$ tabel $(5,14)$ dengan nilai signifikansi $0,132>0,05$ artinya CR dan DER secara simultan tidak berpengaruh signifikan terhadap ROI. Koefisien determinasi $\left(\mathrm{R}^{2}\right)$ sebesar 0,491 yang menunjukkan bahwa sebesar $49,1 \%$ pengaruh perubahan ROI dapat dijelaskan oleh variabel CR dan DER, sedangkan 50,9\% dipengaruhi oleh variabel lain.
\end{abstract}

Kata kunci :Current Ratio (CR), Debt to Equity Ratio (DER), Return On Investment (ROI).

\section{ABSTRACT}

The purpose of this research is to know the employee Stress at PT. PLN (Persero) Bintaro Area, to know the performance of employees at PT. PLN (Persero) Bintaro Area and to know the Influence of Work Stress on Performance at PT. PLN (Persero) Bintaro Tangsel Area.

This research uses quantitative descriptive method, data collection technique with library study and field study, such as: interview, observation and questionnaire. Population in this research is all employees of PT. PLN (Persero) Area Bintaro which amounted to 97 people / respondents. The sample in this study amounted to 97 people / respondents. Data obtained from the questionnaire distribution then analyzed the validity test, reliability test, Regression Simple, product moment correlation test, coefficient of determination and hypothesis test.

From the analysis results obtained product moment correlation coefficient obtained by 0.509 means have a strong enough influence. From result of calculation by using coefficient determination result is $56,85 \%$ this matter mean employee performance influenced by Work Stress equal to $24,8 \%$ while the rest equal to 75,2\% influenced by other factors Besides Discipline like Leadership, Work environment. between Working Stress on employee performance Based on the results show thitung> ttable ie tcount $(5,606)>$ ttabel $(1,987)$ which means that Ho is rejected and Ha accepted, meaningSters Work $(\mathrm{X})$ has a positive and significant impact on employee performance $(\mathrm{Y})$.

Keywords: Job Stress and Employee Performance. 


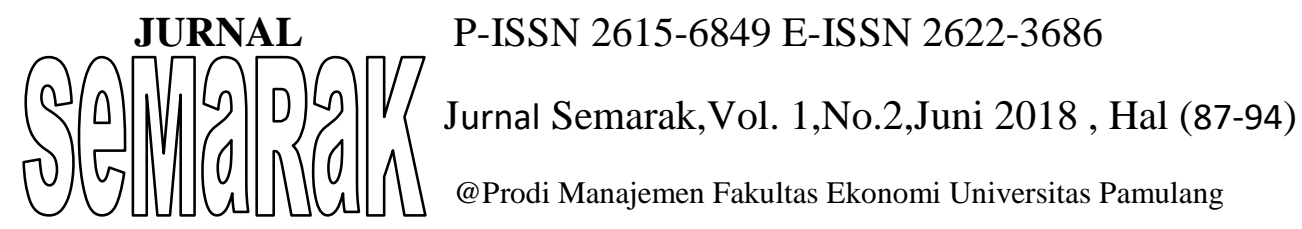

\section{PENDAHULUAN}

\section{A. Latar Belakang}

Krisis ekonomi global adalah peristiwa di mana seluruh sektor ekonomi pasar dunia mengalami keruntuhan/degresi dan mempengaruhi sektor lainnya di seluruh dunia. Tak terkecuali krisis yang terjadi di Indonesia pada tahun 1998, ekonomi Indonesia mengalami kontraksi begitu hebat. Hanya dalam waktu satu tahun, perubahan dramatis terjadi. Prestasi ekonomi yang dicapai dalam dua dekade tenggelam begitu saja. Dia juga sekaligus membalikkan semua impian indah dan cerah di depan mata menyambut milenium ketiga. Selama periode sembilan bulan pertama 1998, tak pelak lagi merupakan periode paling hiruk pikuk dalam perekonomian. Krisis sudah berjalan enam bulan selama tahun 1997, berkembang semakin buruk dalam tempo cepat. Dampak krisis pun mulai dirasakan secara nyata oleh masyarakat, dunia usaha juga termasuk didalamnya. Puluhan bahkan ratusan perusahaan mulai dari skala kecil hingga konglomerat bertumbangan. Sekitar $70 \%$ lebih perusahaan yang tercatat di pasar modal juga insolvent atau nota bene bangkrut.

Menurut Kasmir (2014:202) Return on Investment (ROI) merupakan rasio yang menunjukkan hasil (return) atas jumlah aktiva yang digunakan dalam perusahaan.

Sedangkan menurut Sofyan Syafri Harahap (2010:303) menyatakan rasio ini menggambarkan sampai sejauh mana modal pemilik dapat menutupi utang-utang kepada pihak luar. Semakin kecil rasio ini semakin baik.

Menurut Sofyan Syafri Harahap (2013:301) Current Ratio menunjukkan sejauh mana aktiva lancar menutupi kewajiban lancar.

Berangkat dari beberapa permasalahan yang telah dikemukakan, penulis tertarik melakukan penelitian lebih lanjut dengan judul "PENGARUH CURRENT RATIO DAN DEBT TO
EQUITY RATIO TERHADAP RETURN ON INVESTMENT PADA PT BHUWANATALA INDAH PERMAI, TBK PERIODE 2007-2015".

\section{A. Perumusan Masalah}

Berdasarkan latar belakang penelitian, maka permasalahan dapat dirumuskan sebagai berikut:

1. Bagaimana Current Ratio pada PT Bhuwanatala Indah Permai Tbk?

2. Bagaimana Debt to Equity Ratio pada PT Bhuwanatala Indah Permai Tbk?

3. Bagaimana Return On Investment PT Bhuwanatala Indah Permai Tbk?

4. Bagaimana pengaruh Current Ratio terhadap Return On Investment PT Bhuwanatala Indah Permai Tbk?

5. Bagaimana pengaruh Debt to Equity Ratio terhadap Return On Investment PT Bhuwanatala Indah Permai Tbk?

6. Bagaimana pengaruh Current Ratio dan Debt to Equity Ratio terhadap Return on Investment secara simultan PT Bhuwanatala Indah Permai Tbk?

\section{B. Tujuan Penelitian}

Tujuan penelitian ini adalah untuk memberikan jawaban atas pertanyaan khusus di atas. Adapun tujuan penelitian adalah:

a. Mengetahui Current Ratio PT Bhuwanatala Indah Permai Tbk

b. Mengetahui Debt to Equity Ratio PT Bhuwanatala Indah Permai Tbk

c. Mengatahui Return On Investment PT Bhuwanatala Indah Permai Tbk

d. Mengetahui pengaruh Current Ratio terhadap Return On Investment PT Bhuwanatala Indah Permai Tbk

e. Mengatahui pengaruh Debt to Equity Ratio terhadap Return On Investment PT Bhuwanatala Indah Permai Tbk

f. Mengetahui pengaruh Current Ratio dan Debt to Equity Ratio terhadap Return on Investment secara simultan PT Bhuwanatala Indah Permai Tbk 


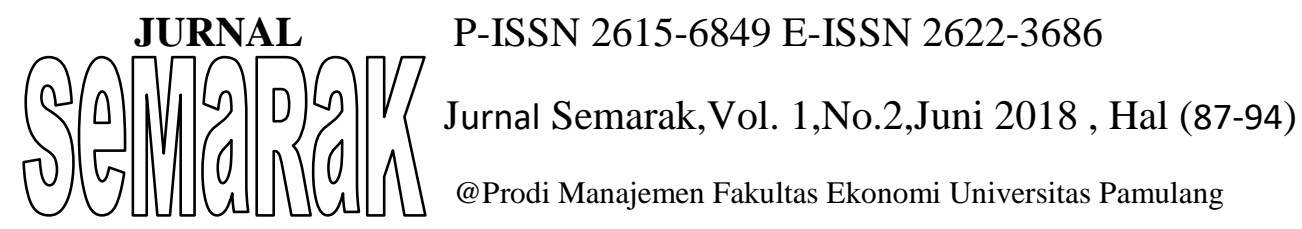

\section{TINJAUAN PUSTAKA}

\section{A. Pengertian Manajemen Keuangan}

Menurut R. Agus Sartono (2010:4)

Manajemen keuangan adalah aktivitas yang berhubungan dengan perolehan, pendanaan, pengolahan aktiva, dengan beberapa tujuan menyeluruh.

James C. Van Horne, sepeti dikutip Kasmir (2010:5) mendefinisikan manajemen keuangan adalah segala aktivitas yang berhubungan dengan perolehan, pendanaan, dan pengolahan aktiva dengan berupa tujuan menyeluruh.

Kasmir (2010:6) juga mengutip pernyataan Brigham yang mengatakan bahwa manajemen keuangan adalah seni (art) dan ilmu (science), untuk me-menage uang, yang meliputi proses, intitusi / lembaga, pasar dan instrumen yang terlibat dengan masalah transfer uang diantara individu. Dari pengertian ini dapat disimpulkan bahwa aktifitas manajemen keuangan berkaitan erat dengan pengelolaan keuangan perusahaan serta instrumen keuangan.

\section{B. Current Ratio}

Rasio lancar atau current ratio merupakan rasio yang mengukur kemampuan perusahaan dalam membayar kewajiban jangka pendek atau utang yang segera jatuh tempo pada saat ditagih secara keseluruhan. (Kasmir, 2014:134)

Menurut Sofyan Syafri Harahap (2013:301) rasio lancar menunjukkan sejauh mana aktiva lancar menutupi kewajibankewajiban lancar.

\section{Debt to Equity Ratio}

Debt to Equity ratio atau rasio utang modal ini menggambarkan sejauh mana modal pemilik dapat menutupi utang-utang kepada pihak luar. Semakin kecil rasio ini semakin baik. Untuk keamanan pihak luar rasio terbaik jika jumlah modal lebih besar dari jumlah utang atau minimal sama.
Menurut Kasmir (2014:157) debt to equity ratio merupakan rasio yang digunakan untuk menilai utang dengan ekuitas. Rasio ini dicari dengan cara membandingkan antara seluruh utang, termasuk utang lancar dengan seluruh ekuitas.

\section{Return On Investment}

Hasil pengembalian investasi atau lebih dikenal dengan nama return on investment (ROI) atau return on total assets merupakan rasio yang menunjukkan hasil (return) atas jumlah aktiva yang digunakan dalam perusahaan. ROI juga merupakan suatu ukuran tentang efektivitas manajemen dalam mengelola investasinya. (Kasmir:201202)

Menurut Munawir (2014:89) return on investment adalah salah satu bentuk dari rasio profitabilitas yang dimaksudkan untuk dapat mengukur kemampuan perusahaan dengan keseluruhan dana yang ditanamkan dalam aktiva yang digunakan untuk operasinya perusahaan untuk menghasilkan keuntungan.

\section{METODE PENELITIAN}

Lokasi dalam penelitian ini adalah wilayah Jakarta Timur dengan produk pepsodent sebagai objek penelitian. Metode yang digunakan dalam penelitian ini adalah metode studi kasus yang merupakan salah satu penelitian deskripti kuantitatif, dengan studi ini diharapkan dapat diungkap secara mendalam variabel-variabel yang menggambarkan tentang analisis kualitas produk, citra merek dan promosi terhadap keputusan pembelian.Pusat Referensi Pasar Modal (PRPM) di gedung Bursa Efek Indonesia (BEI) yang berlokasi di Jl. Jendral Sudirman Kav. 52-53 Jakarta 12190 pada PT Bhuwanatala Indah Permai yang beralamat di Graha BIP lantai $6 \mathrm{Jl}$. Gatot Subroto Kav.23 Jakarta.

Data yang digunakan adalah menggunakan data kuantitatif dan data kualitatif. Data Kuantitatif yangberupa laporan keuangan PT Bhuwanatala Indah 


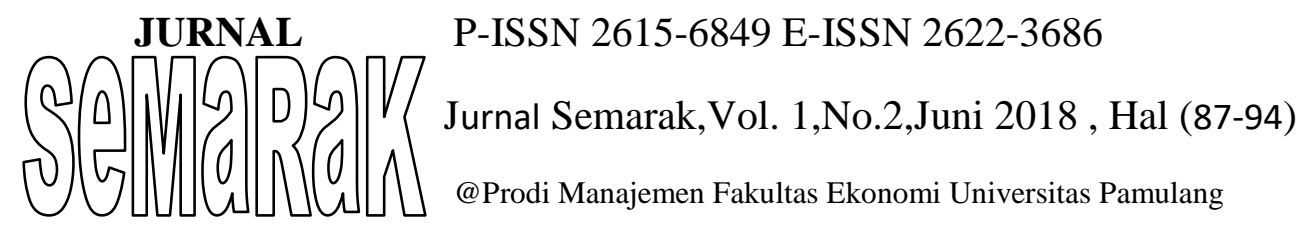

Permai Tbk dari tahun 2007 sampai tahun 2015. Teknik pengumpulan data Kualitatif dengan Data ini berupa sejarah PT Bhuwanatala Indah Permai Tbk dan struktur perusahaan.

Data dan informasi yang diperoleh dari lapangan dianalisis dengan berpedoman kepada kerangka landasan analisis pada pendekatan masalah, yaitu untuk mengetahui pengaruh current ratio dan debt to equity ratio terhadap return on investmentpadaPT. Bhuwanatala Indah Permai, tbk.

\section{HASIL DAN PEMBAHASAN A. Sejarah Singkat PT Bhuwanatala Indah Permai}

PT Bhuwanatala Indah Permai Tbk (perusahaan) pada awalnya didirikan dalam rangka Undang-Undang Penanaman Modal Dalam Negeri No.6 tahun 1968 jo. UndangUndang No. 12 tahun 1970 berdasarkan Akta No.165 tanggal 21 Desember 1981 yang dibuat dihadapan Notaris Koswara, SH. Akta Pendirian tersebut telah mendapatkan pengesahan dari Menteri Kehakiman Republik Indonesia dalam Surat Keputusan No. C2-4821.HT.01.01.Th.83 tanggal 29 Juni 1983 serta diumumkan dalam Lembaran Berita Negara Republik Indonesia No.12 tanggal 10 Februari 1989, Tambahan No.204.

Pada tanggal 26 Juni 1989, PT Bhuwanatala Indah Permai memperoleh izin dari Menteri Keuangan untuk melakukan Penawaran Umum Perdana Saham Bhuwanatala Indah Permai (IPO) kepada masyarakat sebanyak 6.500.000.Saham-saham tersebut telah dicatatkan pada Bursa Paralel Indonesia tanggal 31 Juli 1989. Kemudian tanggal 31 Januari 1990 dilakukan pencatatan 9.500.000 saham PT Bhuwanatala Indah Permai milik pemegang saham pendiri, sehingga seluruh saham PT Bhuwanatala Indah Permai tercatat di Bursa Paralel Indonesia.

\section{B. Pengujian Asumsi Klasik}

1. Hasil Pengujian Persyaratan Analisis (Uji Asumsi Klasik)

a. Hasil Pengujian Normalitas Data Hasil Uji Normalitas Data Secara Grafik

\section{Gambar. 1}

Hasil Uji Normalitas Data Secara Grafik

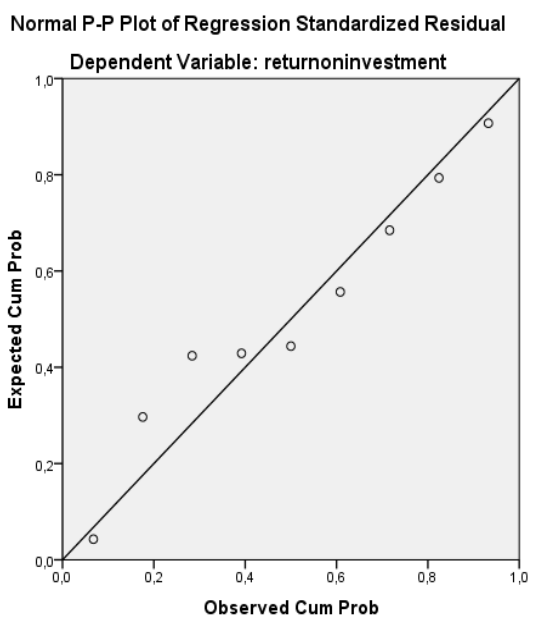

Sumber: Data diolah

Pada grafik normal plot terlihat titiktitik menyebar di sekitar garis diagonal, serta penyebarannya mengikuti arah garis

Tabel. 2

Hasil Uji Kolmogrov Smirnov One-Sample Kolmogorov-Smirnov Test

\begin{tabular}{|c|c|c|}
\hline & & $\begin{array}{l}\text { Unstandardiz } \\
\text { ed Residual }\end{array}$ \\
\hline $\mathrm{N}$ & & 9 \\
\hline Normal Parameters ${ }^{\mathrm{a}, \mathrm{b}}$ & Mean &, 0000000 \\
\hline & $\begin{array}{l}\text { Std. } \\
\text { Deviation }\end{array}$ & 8,32259929 \\
\hline Most Extreme & Absolute & 190 \\
\hline Dimerences & $\begin{array}{l}\text { Positive } \\
\text { Negative }\end{array}$ & $\begin{array}{r}, 120 \\
-, 190\end{array}$ \\
\hline Test Statistic & & ,190 \\
\hline Asymp. Sig. (2-tailed) & &, $200^{\mathrm{c}, \mathrm{d}}$ \\
\hline a. Test distribution is $\mathrm{Nc}$ & nal. & \\
\hline b. Calculated from data & & \\
\hline c. Lilliefors Significance & orrection. & \\
\hline d. This is a lower bound & the true sic & ce. \\
\hline
\end{tabular}

diagonal. Kedua grafik ini menunjukkan bahwa model regresi layak dipakai karena asumsi normalitas (Ghozali 2009:112). 


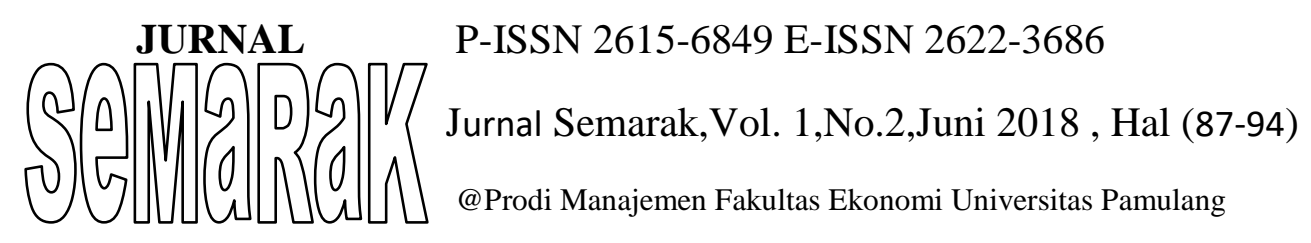

\section{$\underline{\text { Hasil Uji Normalitas Data Secara Statistik }}$}

Berdasarkan uji kolmogorov-smirnov dapat ditarik kesimpulan nilai test statistik 0,190 dan asymp.sig ( 2 tailed) memiliki nilai signifikansi sebesar 0,200. Karena signifikansi lebih besar dari 0,05, maka dapat disimpulkan data berdistribusi normal.

b. Hasil Pengujian Multikolinearitas Berikut hasil uji multikoloniaritas:

Tabel. 3

\section{Uji Multikolinearitas}

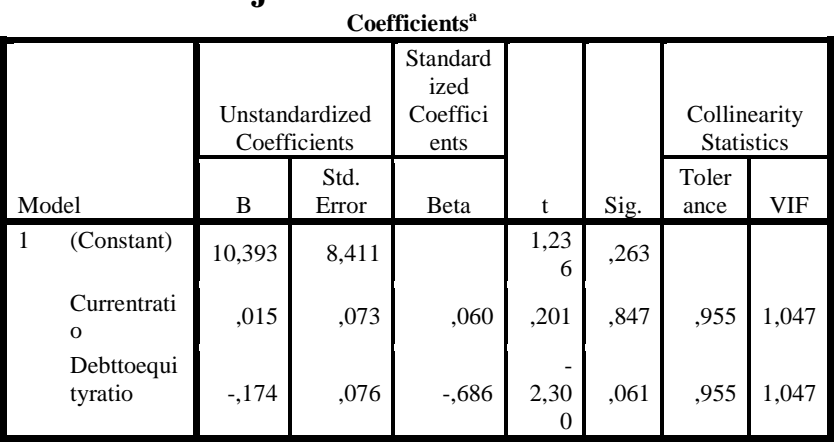

a. Dependent Variable: returnoninvestment

Tabel di atas menjelaskan bahwa data yang ada tidak terjadi gejala multikolinearitas antara masing-masing variabel independen yaitu dengan melihat nilai $V I F$. Nilai $V I F$ yang diperbolehkan hanya mencapai 10 maka data di atas dapat dipastikan tidak terjadi gejala multikolinearitas. Karena data di atas menunjukan bahwa nilai VIF kurang dari 10 . Jadi dapat disimpulkan bahwa dalam model regresi tidak terjadi masalah multikolinearitas.

c. Hasil Pengujian Hetroskedastisitas

Uji heteroskedastisitas bertujuan untuk menguji apakah dalam model regresi terjadi ketidaksamaan variance dari residual satu pengamatan yang lain, berikut hasil pengujian

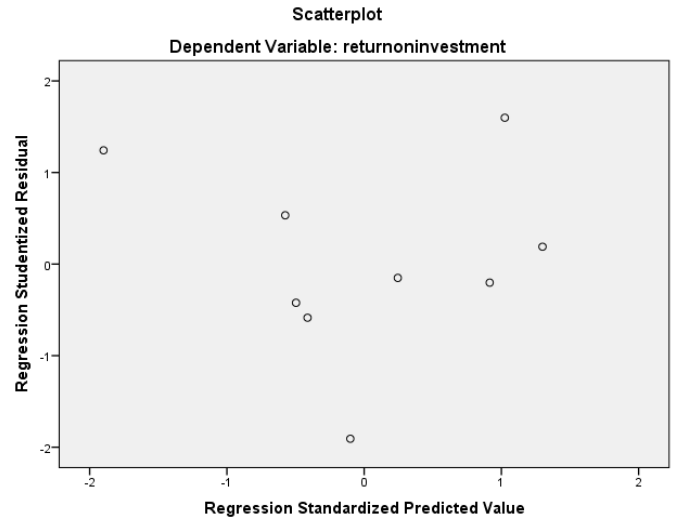

hetroskedastisitas:

Dari grafik scatterplot yang ada pada gambar di atas dapat dilihat bahwa titik-titik menyebar secara acak, serta tersebar baik di atas maupun dibawah angka nol pada sumbu Y. Hal ini dapat disimpulkan bahwa tidak terjadi heteroskedastisitas pada model regresi. (Ghozali 2009:107).

2. Hasil Koefisien Persamaan Regresi Linier Berganda

Berikut adalah hasil koefisien regresi linier berganda:

\section{Tabel 4}

\section{Hasil Analisis Regresi Berganda}

\begin{tabular}{|c|c|c|c|c|c|c|}
\hline \multirow[b]{2}{*}{ Model } & & \multicolumn{2}{|c|}{$\begin{array}{c}\text { Unstandardized } \\
\text { Coefficients }\end{array}$} & \multirow{2}{*}{$\begin{array}{c}\text { Standardized } \\
\text { Coefficients } \\
\text { Beta }\end{array}$} & \multirow[b]{2}{*}{$\mathrm{T}$} & \multirow[b]{2}{*}{ Sig. } \\
\hline & & $\mathrm{B}$ & Std. Error & & & \\
\hline \multirow[t]{3}{*}{1} & (Constant) & 10,393 & 8,411 & & 1,236 & 263 \\
\hline & Currentratio &, 015 &, 073 &, 060 & ,201 &, 847 \\
\hline & Debttoequityratio &,- 174 & ,076 &,- 686 & $-2,300$ & 061 \\
\hline
\end{tabular}

Pada persamaan regresi di atas menunjukkan nilai konstanta sebesar(10,393) menyatakan bahwa jika variabel bebas (Current Ratio dan Debt to Equity Ratio) dianggap konstan sama dengan nol (0), maka nilai Return On Investment adalah (10,393). Koefisien regresi pada variabel Current Ratio sebesar $(0,015)$ dan betanda positif, hal ini berarti bahwa setiap perubahan 1 satuan pada perubahan Current Ratio dengan asumsi variabel lainya tetap, maka Return On Investment akan mengalami perubahan sebesar 0,015 dengan arah yang sama atau searah. Koefisien regresi pada variabel Debt to Equity Ratio sebesar $(-0,174)$, hal ini 


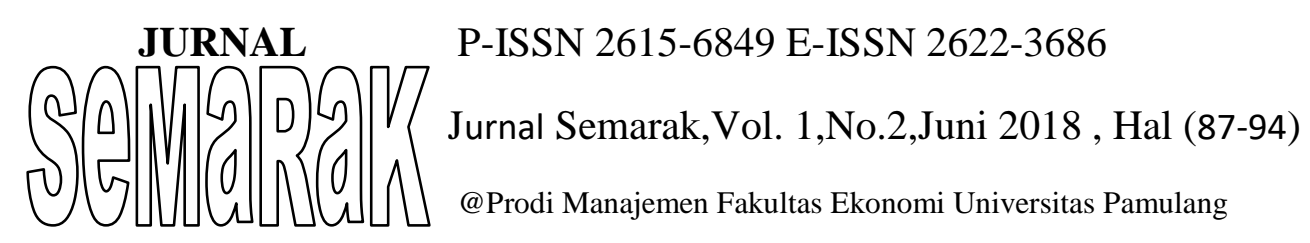

berarti bahwa setiap perubahan 1 satuan pada perubahan Debt to Equity Ratio dengan asumsi variabel lainya tetap, maka Return on Investment akan mengalami perubahan sebesar (-0,174) dengan arah yang berlawanan.

3. Hasil Koefisien Determinasi (Adjusted $R^{2}$ )

Berikut adalah hasil koefisien Determinasi (Adjusted $R^{2}$ ):

Tabel. 5

Uji Determinasi Model Summary ${ }^{\mathrm{b}}$

\begin{tabular}{|l|c|r|r|c|}
\hline Model & $\mathrm{R}$ & R Square & $\begin{array}{c}\text { Adjusted } \\
\text { R Square }\end{array}$ & $\begin{array}{c}\text { Std. Error } \\
\text { of the } \\
\text { Estimate }\end{array}$ \\
\hline 1 &, $701^{\mathrm{a}}$ &, 491 &, 321 & 9,61011 \\
\hline
\end{tabular}

a. Predictors: (Constant), debttoequityratio,

currentratio

b. Dependent Variable: returnoninvestment

Berdasarkan kepada tabel di atas jadi dapat di simpulkan bahwa current ratio dan debt to equity ratio berpengaruh sebesar $49,1 \%$ terhadap return on investment sedangkan sisanya $50,9 \%$ di pengaruhi oleh variabel lain yang tidak di teliti di dalam penelitian ini.

4. Hasil Pengujian Hipotesis

a. Hasil Uji F (Pengujian Secara Simultan)

Berikut adalah hasil uji F:

Tabel. 8

Hasil Uji F (Simultan) ANOVA $^{a}$

\begin{tabular}{|c|c|c|c|c|c|c|}
\hline \multicolumn{2}{|c|}{ Model } & $\begin{array}{l}\text { Sum of } \\
\text { Squares }\end{array}$ & Df & $\begin{array}{c}\text { Mean } \\
\text { Square }\end{array}$ & $\mathrm{F}$ & Sig. \\
\hline 1 & $\begin{array}{l}\text { Regressi } \\
\text { on }\end{array}$ & 534,287 & 2 & 267,144 & 2,893 &, $132^{\mathrm{b}}$ \\
\hline & Residual & 554,125 & 6 & 92,354 & & \\
\hline & Total & 1088,413 & 8 & & & \\
\hline
\end{tabular}

Hasil uji F hitung adalah 2,893 (lihat pada tabel ANOVA) . F kritis dapat dicari pada tabel statistik pada signifikansi 0,05, df $1=\mathrm{k}-1$ atau $3-1=2$, dan df $2=\mathrm{n}-\mathrm{k}$ atau 9-3 $=6$ ( $\mathrm{k}$ adalah jumlah variabel). Di dapat $\mathrm{F}$ kritis adalah 5,14. Dapat diketahui bahwa $\mathrm{f}_{\text {hitung }}(2,893) \leq \mathrm{F}_{\text {tabel }}(5,14)$ jadi $\mathrm{H}_{0}$ diterima, kesimpulannya yaitu current ratio dan debt to equity ratio secara serentak tidak berpengaruh signifikan terhadap return on investment.
b. Hasil Uji t (Pengujian Secara Parsial)
Berikut adalah hasil uji t:

\section{Tabel 6}

Hasil Uji T

\begin{tabular}{|c|c|c|c|c|c|c|}
\hline \multirow{2}{*}{\multicolumn{2}{|c|}{ Model }} & \multicolumn{2}{|c|}{$\begin{array}{l}\text { Unstandardized } \\
\text { Coefficients }\end{array}$} & $\begin{array}{c}\text { Standardized } \\
\text { Coefficients }\end{array}$ & \multirow[t]{2}{*}{$\mathrm{T}$} & \multirow[t]{2}{*}{ Sig. } \\
\hline & & $\mathrm{B}$ & Std. Error & Beta & & \\
\hline 1 & $\begin{array}{l}\text { (Constant) } \\
\text { Currentratio }\end{array}$ & $\begin{array}{c}-5,237 \\
, 050\end{array}$ & $\begin{array}{c}6,296 \\
, 091\end{array}$ & ,205 & $\begin{array}{r}, 832 \\
, 553\end{array}$ & $\begin{array}{l}, 433 \\
, 597\end{array}$ \\
\hline 2 & $\begin{array}{l}\text { (Constant) } \\
\text { ttoequityratio }\end{array}$ & $\begin{array}{r}11,424 \\
-, 177\end{array}$ & $\begin{array}{r}6,189 \\
, 069\end{array}$ &,- 698 & $\begin{array}{l}1,846 \\
-2,580\end{array}$ & $\begin{array}{l}, 107 \\
, 036\end{array}$ \\
\hline
\end{tabular}

Predictors: (Constant), debttoequityratio, currentratio

Berdasarkan tabel di atas dapat dilihat bahwa pengaruh current ratiodiketahui bahwa t hitung $0,553<\mathrm{t}$ kritis 2,447 dengan signifikansi $0,597>0,05$ sehingga $\quad \mathrm{H}_{0}$ diterima, kesimpulannya current ratio tidak berpengaruh signifikan terhadap return on investment.dapat dilihat bahwa pengaruhdebt to equity ratiot kritis adalah 2,447. Maka dapat diketahui bahwa t hitung $(-2,580)<\mathrm{t}$ kritis 2,447 dengan signifikansi $0,036<0,05$ sehingga $\mathrm{H}_{0}$ ditolak, kesimpulannya debt to equity ratio berpengaruh signifikan terhadap return on investment.

\section{KESIMPULAN DAN SARAN}

\section{A. Kesimpulan}

Berdasarkan pada hasil penelitian dan pembahasan mengenai pengaruh Current ratio, debt to equity ratio terhadapretrun on investment, maka penulis dapat menarik beberapa kesimpulan sebagai berikut:

1. Berdasarkan hasil penelitian secara parsial, variabel current ratio tidak berpengaruh signifikan terhadap return on investment PT Bhuwanatala Indah Permai Tbk dengan melihat signifikansi $0,597>0,05$ dan hasil persamaan regresinya adalah $\mathrm{Y}=(-5,237)+0,050 \mathrm{X}$. 


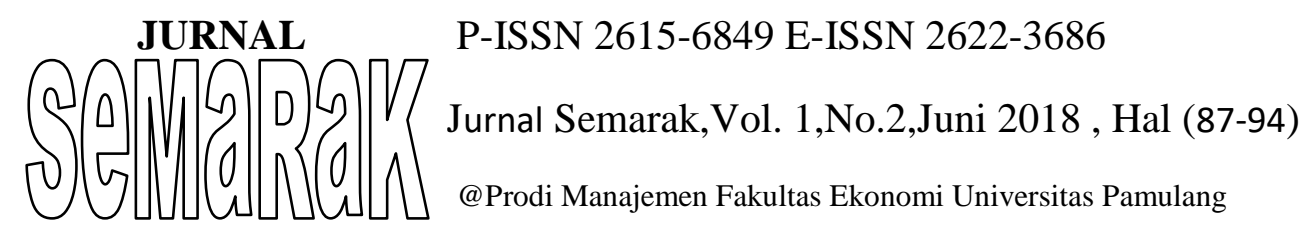

2. Berdasarkan hasil penelitian secara parsial, variabel debt to equity ratio PT Bhuwanatala Indah Permai Tbk berpengaruh secara signifikan terhadap return on investment dengan tingkat signifikansi $0,036<0,05$ dan hasil persamaan regresinya adalah $\mathrm{Y}=11,424$ $+(-0,177) \mathrm{X}$.

3. Hasil penelitian ini menunjukkan bahwa Current Ratio dan Debt to Equity Ratio berkontribusi terhadap Return On Investment sebesar $49.1 \%$ sedangkan sisanya 50,9\% merupakan kontribusi dari variabel lain yang tidak diteliti di dalam penelitian ini. Hasil persamaan regresi linier bergandanya adalah $\mathrm{Y}=10,393+0,015 \mathrm{X}_{1}+(-0,174) \mathrm{X}_{2}$. Dan berdasarkan penelitian secara simultan variabel Current Ratio dan Debt to Equity Ratio tidak berpengaruh signifikan terhadap Return On Investment PT Bhuwanatala Indah Permai Tbk dilihat dari $\mathrm{F}_{\text {hitung }}(2,893)<$ $F_{\text {tabel }}(5,14)$.

\section{B. Saran}

Saran yang dapat dijadikan masukan dari peneliti kepada perusahaan yang sejenis industri yaitu :

1. Pengambilan keputusan terkait dengan keputusan investasi, lakukan secara terperinci agar investasi yang ditanamkan menghasilkan keuntungan pada perusahaan yang akan berdampak pada laba perusahaan.

2. Perusahaan harus mengelola dengan baik dana-dana yang masuk, aktiva yang dimiliki, dan mengelola kegiatan perusahaan dengan baik agar tidak merugikan investor.

3. Perusahaan harus mengembangkan beberapa usaha yang telah direncanakan dengan secermat mungkin agar dapat bersaing dengan perusahaan sejenis.

\section{DAFTAR PUSTAKA}

Fahmi, Irham. "Analisis Kinerja Keuangan", Cetakan Ke Satu, Alfa Beta CV, Bandung, 2011.

Fahmi, Irham. “ Pengantar Manajemen Keuangan", Cetakan Pertama, Alfa Beta CV, Bandung, 2012.

Harahap, Sofyan. "Analisis Kritis atas Laporan Keuangan", Cetakan kesebelas, PT. Raja Grafindo Persada : Jakarta, 2013.

Kasmir, "Analisis Laporan Keuangan”, Penerbit Rajawali Pers : Jakarta, 2014.

Kasmir, "Pengantar Manajemen Keuangan", Cetakan Kedua, Kencana Prenada Media Group : Jakarta, 2010.

Munawir, "Analisis Laporan Keuangan", Liberty : Yogyakarta, 2010.

Munawir, "Analisis Laporan Keuangan", Edisi Keempat, Cetakan Ke 15, Liberty : Yogyakarta, 2013.

Riyanto, Bambang. "Dasar-Dasar Pembelanjaan

Perusahaan",BPFE,

Yogyakarta, 2009.

Riyanto, Bambang. "Dasar-Dasar Pembelanjaan Perusahaan", Edisi Empat, BPFE : Yogyakarta, 2011.

Sartono, Agus. "Manajemen Keuangan Teori dan Aplikasi", (4th ed), Yogyakarta: BPFE, 2010.

Sugiyono, "Metode Penelitian Kualitatif, Kuantitatif dan Kombinasi", Alfabeta : Bandung, 2011. 


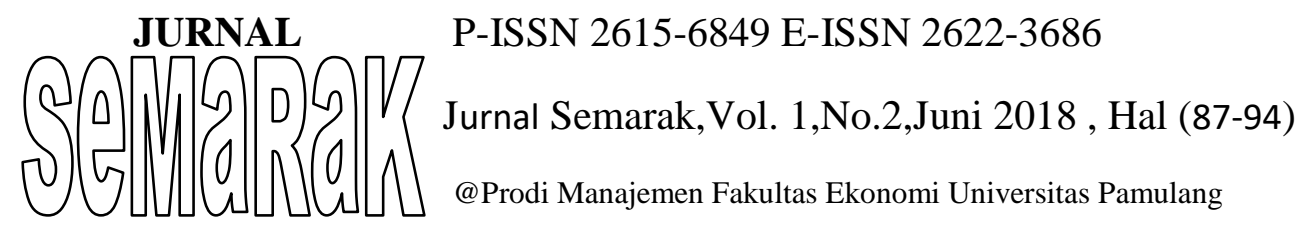

Ghozali, Imam. "Aplikasi Analisis Multivariate dengan Program IBM SPSS 19",

Semarang : Badan Penerbit Sudarmo, Universitas Diponegoro. 2011.

Brigham dan Houston, “ DasarDasarManajemen", EdisiKe 11, BukuPertama, SalembaEmpat: Jakarta, 2010.

Bungin, Burhan. "AnalisisPenelitian Data Kualitatif", Raja Grafindo:Jakarta,2009.

D. Agus Harjito dan Martono, "Manajemen Keuangan", Cetakan Ketiga, Edisi Kedua, Ekonisia, Yogyakarta, 2013.

Drs. Dwi Prastowo D., MM, Akuntan Rifka Julianty, "AnalisisLaporanKeuangan", Edisi Kedua, Unit Penerbitdan Percetakan Sekolah Tinggi Ilmu Manajemen (YKPN), Yogyakarta, 2008.

Handoko, Hani. "Manajemen", Edisi Kedua, Cetakan Ke 21, BPFE : Yogyakarta,2011.

Lukman, Syamsudin. "ManajemenKeuangan Perusahaan", PT. Raja Grafindo Persada : Jakarta, 2007.

Prasetyo, Bambang, "MetodologiPenelitian", Edisi 1-5, Rajawali Pers : Jakarta,2010.

Sawir, Agnes, "AnalisisKinerjaKeuangandan PerencanaanKeuangan Perusahaan", PT. Gramedia Pustaka Utama, Jakarta, 2009.
Subramanyan, "AnalisisLaporanKeuangan", Edisi Ke 10, Salemba Empat: Jakarta, 2010.

Gito, "Dasar-
DasarAkutansiBiaya", BPFE :
Yogyakarta,2010.

Hanafi M Mamduh dan Halim Abdul, "Analisis Laporan keuangan", Edisi Keempat, Cetakan Kedua, Sekolah Tinggi Ilmu Manajemen (YKPN) : Yogyakarta, 2012.

Hanafi M Mamduh dan Halim Abdul, "Analisis Laporan Keuangan", Edisi Keempat, Cetakan Pertama, Sekolah Tinggi Ilmu Manajemen (YKPN) : Yogyakarta, 2010.

Husnan, Suad. "Manajemen Keuangan", Edisi Kedua, Cetakan Keenam, Penerbit Universitas Terbuka : Jakarta, 2011.

Kuncoro, Mudrajad. "Metode Riset Untuk Bisnis dan Ekonomi", Edisi 3, Erlangga : Yogyakarta, 2009.

Manullang, "Dasar-Dasar Manajemen", Cetakan Ke 21, Gadjah Mada University Press : Yogyakarta, 2009.

Sutrisno,"Manajemen Keuangan", Ekonisia, Kampus Ekonomi UI : Yogyakarta,2013.

Wijayanto, Dian. "Pengantar Manjemen”, PT. Gramedia Pustaka Utama, : Jakarta,2012.

Arikunto, Suharsimi, "Prosedur Penelitian Suatu Pendekatan Praktik", Edisi Revisi 6, Rineka Cipta, Jakarta, 2009. 